\title{
Relationship between Physical Activity, Anthropometry, and Forced Expiratory Volume in One Second with 6-Minute Walk Distance in Elderly
}

\author{
Irna Purnamasari Sukarya, Vitriana, Tertianto Prabowo
}

Department of Physical Medicine and Rehabilitation, Faculty of Medicine, Universitas Padjadjaran-Dr. Hasan Sadikin General Hospital

\begin{tabular}{|c|c|}
\hline \multirow[t]{3}{*}{ Abstract } & $\begin{array}{l}\text { Objective: To examine the correlation between physical activity using the } \\
\text { Global Physical Activity Questionnaire (GPAQ), anthropometry (body mass } \\
\text { index/BMI), and forced expiratory volume in one second (FEV }{ }_{1} \text { ) value with } \\
\text { six-minute walk distance in healthy community-dwelling elderly. }\end{array}$ \\
\hline & $\begin{array}{l}\text { Methods: A cross-sectional design study with consecutive sampling was } \\
\text { conducted. This study included sixty nine participants }(30 \text { males and } 39 \\
\text { females), aged } \geq 60 \text { years who lives at Batununggal region in Bandung, } \\
\text { Indonesia. The data was analyzed statistically by using normality, correlation, } \\
\text { and multiple regresion tests. }\end{array}$ \\
\hline & $\begin{array}{l}\text { Results: The results showed that there was a correlation between six- } \\
\text { minute walk distance and BMI in females }(p=0.006) \text {, and FEV value in males } \\
(p=0.010) \text {. No significant correlation was found between GPAQ value and six- } \\
\text { minute walk distance in females }(p=0.4074) \text { and in males }(p=0.0926) \text {. }\end{array}$ \\
\hline $\begin{array}{l}\text { Received: } \\
\text { December 14, } 2016\end{array}$ & $\begin{array}{l}\text { Conclusions: There was a correlation between anthropometry and FEV } \text {, value }_{1} \\
\text { with six-minute walk distance in healthy elderly. There was no significant } \\
\text { correlation between physical activity and six-minute walk distance. }\end{array}$ \\
\hline $\begin{array}{l}\text { Revised: } \\
\text { March 16, } 2017\end{array}$ & $\begin{array}{l}\text { Keywords: Anthropometric measurement, } \mathrm{FEV}_{1} \text {, physical activity, six-minute } \\
\text { walk distance }\end{array}$ \\
\hline March 17, 2017 & $\begin{array}{l}\text { pISSN: 2302-1381; eISSN: 2338-4506; http://doi.org/10.15850/ijihs.v5n1.963 } \\
\text { IJIHS. 2017;5(1):30-5 }\end{array}$ \\
\hline
\end{tabular}

\section{Introduction}

Aging is a natural phase in humans results in some changes in the body compositions and skeletal muscles. Muscle mass loss is associated with infiltration of fat and connective tissues into the muscle fibers. This leads to structural redistributions with the decrease of muscle strength and function which may affect some physical performances. Muscle strength and function may decrease $1-2 \%$ per year at 50 years of age and above, results in significant decreases of some physical functions including cardiopulmonary functions, physical activity, and quality of life in elderly. ${ }^{1-3}$

\footnotetext{
Correspondence:

Irna Purnamasari Sukarya, Department of Physical Medicine and Rehabilitation, Faculty of Medicine, Universitas Padjdajaran-Dr. Hasan Sadikin General Hospital

Jl. Pasteur No. 38, Bandung, Indonesia

e-mail: irna.purnamasari@yahoo.com
}

Cardiopulmonary system changes may occur in consort with significant decline of aerobic capacity in the elderly population. Previous studies stated that cardiopulmonary fitness becomes a vital factor which influences the physical performance. Cardiopulmonary fitness can decrease approximately 15\% per decade after 30 years of age. ${ }^{1,3,4}$

There were several distinctive variables that significantly influence respiratory function such as age, sex, height, race, ethnic, smoking history, environment condition, measurement tools, and test methods. Aging process causes several changes in body, including respiratory muscle mass, gas exchange, and control of ventilation. Increased rigidity of the chest wall and decreased respiratory muscle strength in elderly can increase the closing capacity and decrease the forced expiration volume in one second $\left(\mathrm{FEV}_{1}\right)$ on pulmonary function tests. ${ }^{5}$

Functional fitness and physical activity 
assessments are inevitably required as an implication to maintain flexibility of movement and quality of life in elderly. Conceptually, functional fitness is the ability in performing daily activities normally and independently without early fatigue. Routine physical activity becomes main factor to maintain flexibility of movement that prevent chronic diseases, and the physical activity assessment along with certain related factors are important for the authorities due to the population surveillance program. ${ }^{1,3,6,7}$

Physical activity assessment can be done using objective and physiological methods, such as $\mathrm{VO}_{2}$ max indirect measurement by cardiopulmonary exercise testing. However, the most common conducted cardiopulmonary exercise testing is the six-minute walk test.

The six-minute walk test is considered as an appropriate cardiopulmonary fitness test, inexpensive, and similar to daily activity. ${ }^{8-12}$ A study in west Australia which involved Caucasian participants aged 55-75 years revealed that six-minute walk distance in males was higher $59 \pm 13$ than in females. ${ }^{11} \mathrm{~A}$ recent study in Brazil which included females with average age 66 years reported that physical activity becomes an important independent predictor toward six-minute walk distance. ${ }^{10}$ Some health conditions in elderly may disturb the ability of walking and become a limitation in performing six-minute walk test, so it is important to find another way to predict the six-minute walk distance for elderly with such condition.
This study aimed to observe the correlation between physical activity using Global Physical Activity Questionnaire (GPAQ), anthropometry (body mass index/BMI), and forced expiration volume in one second $\left(\mathrm{FEV}_{1}\right)$ value with sixminute walk distance in healthy communitydwelling elderly population.

\section{Methods}

The participants involved in this study were the healthy elderly citizens at Batununggal region, Bandung, Indonesia. The inclusion criterias in this study were elderly aged $\geq 60$ years and able to comprehend the instruction with the mini mental status examination (MMSE) score $\geq 24$. The exclusion criterias were those who had uncontrolled cardiovascular and pulmonary diseases, stroke, uncontrolled hypertension, and those with deformities or lower extremity disorders which affect walking ability.

The data of physical activity in this study were collected by conducting questionnaire distribution. The participants were asked several questions based on GPAQ through guided interview to obtain the total score of physical activity level. The questionnaire is suitable to collect information relating to the participant physical activity in sedentary and three domains: (1) occupational activity, (2) traveling from and to another place, and (3) recreational activity. ${ }^{6,7}$

Anthropometric measurements of BMI were performed using bioelectrical impedance

Table 1 Participant General Data Distribution

\begin{tabular}{lcccc}
\hline \multirow{2}{*}{$\begin{array}{c}\text { Respondent } \\
\text { Characteristics }\end{array}$} & \multicolumn{2}{c}{ Females (n=39) } & \multicolumn{2}{c}{ Males (n=30) } \\
\cline { 2 - 5 } & $66.69(5.72)^{*}$ & 65 & $66.83(6.71)^{*}$ & 64.5 \\
\hline Age (years) & $11.12(3.71)^{*}$ & 12 & $12.83(3.87)^{*}$ & 12 \\
Education history (years) & $59.79(12.20)$ & 59.7 & $61.83(10.32)$ & 64.5 \\
Body weight (kg) & $151.62(5.80)$ & 153 & $163.12(4.64)$ & 163 \\
Body height (cm) & $25.94(4.95)^{*}$ & 25.8 & $23.91(2.64)^{*}$ & 24.3 \\
BMI (kg/m $\left.{ }^{2}\right)$ & $391.84(59.67)$ & 390 & $444.96(90.19)$ & 440 \\
6-minute walk distance (m) & $1.56(0.30)$ & 1.59 & $2.12(0.43)$ & 2.185 \\
FEV $_{1}(\mathrm{~L})$ & $4,169.74(4,152.44)^{*}$ & 3480 & $2,520.66(3,356.23)^{*}$ & 1680 \\
GPAQ & & & & \\
\hline
\end{tabular}

Notes: $\mathrm{BMI}=$ body mass index $; \mathrm{FEV}_{1}=$ forced expiration volume in one second; GPAQ=Global Physical Activity Questionnaire

*non-normally distributed data using normality Saphiro Wilks test 
analysis (BIA/Tanita BC601, Tanita Corp, Tokyo, Japan) in kilogram and $\mathrm{kg} / \mathrm{m}^{2}$. Forced expiration volume in one second was measured by using a spirometer (Chestgraph HI-101, Chest M.I.Inc, Tokyo, Japan). A pulse oxymeter (CTO fingertip pulse oxymeter) was applied on the thumb of left hand while performing spirometry and six-minute walk test.

Before and after the six-minute walk test, several assessments were performed such as measurement of blood pressure, heart rate, and rating of perceived exertion by Borg scale. The participants were then instructed to walk on a 30-meter walking track. The distance of the six-minute walk test were recorded.

The statistical test was used to determine the relationship between physical activity, anthropometry, and FEV ${ }_{1}$ value with the distance of six-minute walk test. The statistical tests used in this study were normality data, descriptive statistic, Pearson and Spearman correlation based on data distribution, and multiple regression tests between the distance of six-minute walk test and physical activity, anthropometry, and $\mathrm{FEV}_{1}$ value. This study was approved by the Health Research Ethic Committee, Faculty of Medicine, Universitas Padjadjaran, Bandung, Indonesia with ethical approval no 153/UN6.C1.3.2/KEPK/PN/2016.

\section{Results}

Eighty participants were invited to participate in this study. Eleven participants did not meet the inclusion criteria and were not included in the study. Therefore, sixty nine participants who met the inclusion criteria in this study were 30 males and 39 males (Table 1).

The relationship between physical activity, anthropometry, and $\mathrm{FEV}_{1}$ value among the participants were discovered (Table 2 and 3). No significant correlation was found between GPAQ value and six-minute walk distance in females $(\mathrm{p}=0.4074)$ and in males $(\mathrm{p}=0.0926)$ (Table 2).

In females, the correlation between sixminute walk distance and FEV $(\mathrm{p}=0.415)$ was not considered statistically significant but a correlation was found between six-minute walk distance and BMI $(\mathrm{p}=0.006)$ (Table 3). However, in males, the correlation between six-minute walk distance and BMI $(p=0.476)$ was not considered statistically significant but a correlation was found between six-minute walk distance with FEV value $(p=0.010)$.

Body mass index and FEV were the main variables which influenced the results and showed significant correlation with six-minute walk distance. The correlation between gender and GPAQ value with six-minute walk distance was not considered statistically significant which showed that GPAQ was not included into the predictive equation. The regression analysis was repeatedly performed which included independent variables, such as BMI and FEV .

Residual descriptive statistical test was then performed by analyzing residual distribution (Saphiro Wilks test). The residual distribution was defined by the normal distribution with mean $=0$ ( $t$ test). In this study, the $t$ value was 0.735328 with $p>0.05$ and mean $=0$. The residual distribution resulted $\mathrm{W}=0.966$ with $\mathrm{p}=0.155$. The results showed that the residual distribution was based on the normal distribution with mean $=0$. Furthermore, the regression test resulted a predictive equation: Six-Minute Walk Distance $=133.583 \times$ FEV1 + $6.593 \times$ BMI.

\section{Discussion}

The six-minute walk distance average value was discovered in females $(391.84 \pm 59.67$ meter) and in males (444.96 \pm 90.19 meter). Male participants show average 53,12 meter distance further than in females. In addition, a study reported similar results that males (690 \pm 62 meter) showed 59 meter distance further when compared to females $(631 \pm 57$ meter). ${ }^{11}$ Several studies relating to physical activity stated that physical activity levels in males and females are distinguished.

A previous study found that physical activity in male elderly were higher than females. ${ }^{13}$ Using a self-reported physical activity method, the data determined that physical activity in males were about $0.8-21.4 \%$ higher than females. Another study with different result revealed that the physical activity using selfreported method discovers that the physical activities in female elderly were higher. ${ }^{14}$

\section{Table 2 Spearman Correlation Test between 6-Minute Walk Distance and GPAQ Value}

\begin{tabular}{lccc}
\hline $\begin{array}{c}\text { 6-minute } \\
\text { walk distance } \\
\text { and GPAQ }\end{array}$ & Spearman & T (N-2) & p Value \\
\hline Female $(\mathrm{n}=39)$ & 0.1365 & 0.8381 & 0.4074 \\
Males $(\mathrm{n}=30)$ & 0.3126 & 1.7412 & 0.0926 \\
\hline
\end{tabular}


Table 3 Pearson Correlation Test between 6-Minute Walk Distance with Anthropometries and Forced Expiration Volume in One Second

\begin{tabular}{lcccc}
\hline 6-minute walk distance (m) & Weight (kg) & Height (cm) & BMI (kg/m2) & FEV $_{\mathbf{1}}(\mathbf{L})$ \\
\hline Females (n=39) & & & & \\
$\quad$ Correlation coefficient (r) & -0.3159 & 0.265 & -0.4306 & -0.1342 \\
p value & 0.05 & 0.103 & $0.006^{*}$ & 0.415 \\
Males (n=30) & & & & \\
Correlation coefficient (r) & 0.1143 & 0.4 & 0.1354 & 0.4644 \\
p value & 0.547 & $0.029^{*}$ & 0.476 & $0.010^{*}$ \\
\hline
\end{tabular}

Notes: BMI: body mass index ; FEV1: forced expiration volume in one second;

$*$ p value $<0.05$

This study discovers that the GPAQ value in females (4169.74 \pm 4152.44$)$ was higher than in males (2520.66 \pm 3356.23$)$. These results may be correlated with Indonesian's culture which still distinguishes between male and female based on biological difference and social participation. Moreover, elderly females play an important role in the society, be able to socialize, and have insignificant decrease of activity level than in males. ${ }^{15}$

There was no correlation found between the physical activity and six-minute walk distance in this study. Based on the Rank Spearman test results, the correlation between physical activity assessed using GPAQ and six-minute walk distance is not considered statistically significant in females and males (Table 2). This can occur because the GPAQ assessment is considered accurate only for assessing vigorous physical activity, compared to light and moderate physical activity.

A review of GPAQ validity data reported that there is higher discrepancy between physical activities assessment using self-report and objective method such as accelerometer for high intensity activities. Different result may occur by other methods of physical activity assessment. ${ }^{7,16}$

Body mass index becomes a common anthropometry parameter correlated with six-minute walk distance. ${ }^{18,19}$ Walk distance can be predicted through several variables, including age, sex, body weight, body height, and BMI which influence $26-66 \%$ distance variability. ${ }^{9,18}$ This study also found that there was a correlation between six-minute walk distance with BMI in females.

An alternative variable such as $\mathrm{FEV}_{1}$ value can be used as a determinant but it potentially causes bias. The correlation strength between $\mathrm{FEV}_{1}$ value and six-minute walk distance in subjects with minimal ventilation is different from the healthy subjects. However, there is a correlation between $\mathrm{FEV}_{1}$ value and

Table 4 Forward Stepwise Regression Analysis Test with Dependent 6-Minute Walk Distance Variable with Adjusted R=0.97245103

\begin{tabular}{lcccccc}
\hline & Beta & $\begin{array}{c}\text { St.Err of } \\
\text { Beta }\end{array}$ & B & St.Err. of B & $\mathbf{t ( 6 4 )}$ & p Value \\
\hline FEV1 & 0.155203 & 0.109523 & 35.10641 & 24.773889 & 1.41707303 & 0.1613 \\
Weight & -0.177682 & 0.11284 & -1.215292 & 0.7717912 & -1.5746377 & 0.1203 \\
Height & 0.981931 & 0.139483 & 2.64373 & 0.3755422 & 7.03976838 & $1.58 \mathrm{E}-09^{*}$ \\
Sex & 0.013716 & 0.033823 & 8.78213 & 21.656821 & 0.40551354 & 0.6865 \\
GPAQ & 0.026762 & 0.027719 & 0.0021817 & 0.0022598 & 0.96547134 & 0.3379 \\
\hline
\end{tabular}

Notes: $\mathrm{FEV}_{1}=$ forced expiration volume in one second; GPAQ=Global Physical Activity Questionnaire ${ }^{*}$ p value $<0.05$ 
Table 5 Forward Stepwise Regression Analysis Test with Dependent 6-Minute Walk DistanceVariable with Adjusted R=0.95280530

\begin{tabular}{lcccccc}
\hline & Beta & $\begin{array}{c}\text { St.Err of } \\
\text { Beta }\end{array}$ & B & St.Err. of B & $\mathbf{t}(\mathbf{6 4 )}$ & p Value \\
\hline FEV1 & 0.0314 & 0.0475 & 20.1263 & 30.4160 & 0.6617 & 0.5105 \\
Weight & 0.4100 & 0.1041 & 6.8118 & 1.7302 & 3.9370 & $0.0002^{*}$ \\
Height & 0.5265 & 0.1265 & 119.1030 & 28.6157 & 4.1622 & $0.0001^{*}$ \\
Sex & 0.0432 & 0.0361 & 0.0035 & 0.0029 & 1.1944 & 0.2367 \\
GPAQ & 0.026762 & 0.027719 & 0.0021817 & 0.0022598 & 0.96547134 & 0.3379 \\
\hline
\end{tabular}

Notes: $\mathrm{FEV}_{1}=$ forced expiration volume in one second; GPAQ=Global Physical Activity Questionnaire ${ }^{*} \mathrm{p}$ value $<0.05$

six-minute walk distance found in chronic obstructive pulmonary disease subjects. ${ }^{18}$ This study discovers a correlation and a significant relationship between FEV1value ( $\mathrm{r}=-0.4644$; $\mathrm{p}=0.010$ ) and six-minute walk distance in male participants. These results are similar to the study in Australia which included 70 elderly participants aged $55-75$ years. ${ }^{11}$ The study reported that height and $\mathrm{FEV}_{1}$ value are independent predictors which show significant correlation with six-minute walk distance, thus, combining the variables will result 33.9\% variation of walk distance.

A study conducted in Singapore discovered 6-minute walk distance predictive equation without distinguishing sex. ${ }^{20}$ The predictive equation is $(5.50 \times \% \mathrm{HR}$ maks $)+(6.94 \mathrm{x}$ height) - (4.49 x age) - (3.51 x weight $)$ 473,27; with $R=0.78$. Another study in 2014 in Indonesia revealed a predictive equation of 6-minute walk distance $=586.254+0.622$ weight $(\mathrm{kg})-0.265$ height $(\mathrm{cm})-63.343$ sex $(0=$ male; $1=$ female $)+0.117$ age, with $R=0.606$ and adjusted R2=0.345.

The equation in this study meets the regression term to predict six-minute walk distance. Residual test and residual equation distribution follow the normally probability distribution with significant value is $>0.05$ $(\mathrm{p}=0.155)$ that determines the equation is considered valid and can be used. Based on the equation, the adjusted $\mathrm{R}$ was $95 \%$ with $\mathrm{FEV}_{\text {, was }}$ 59\% (Beta=0.5906) and BMI was $39 \%$ (Beta $=0.3968$ ) toward six-minute walk distance. The equation is properly used to predict six-minute walk distance in elderly females and males. The variables contribute $98 \%$ while another $2 \%$ is predicted by using other variables.

In conclusion, there was a correlation between anthropometry and $\mathrm{FEV}_{1}$ value with six-minute walk distance, therefore, there was no significant correlation between physical activity with six-minute walk distance in healthy elderly. There are several limitations in this study. The method used for assessing the physical activities was inproper to apply in elderly population due to the intensity of the activities. Further study may use other methods which are sensitive for light and moderate physical activities, or by applying an objective assessment with accelerometer. This study also did not differentiate the healthy and minimal ventilation participants, that may become a consideration in the further study to homogenize lung function to decrease bias that might be appeared in the results.

\section{References}

1. Milanović Z, Pantelić S, Trajković N, Sporiš G, Kostić R, James N. Age-related decrease in physical activity and functional fitness among elderly men and women. Clin Interv Aging. 2013;8:549-56.
2. Bautmans I, Lambert M, MetsT. The six-minute walk test in community dwelling elderly: influence of health status. BMC Geriatrics [serial on the internet]. 2004 July [cited 2016 Aug 12];4(6):[about 9p.]. Available from: 
https: / /bmcgeriatr.biomedcentral.com / articles/10.1186/1471-2318-4-6.

3. Leyk D, Rüther T, Wunderlich M, Sievert A, Essfeld D, Witzki A, et al. Physical performance in middle age and old age: good news for our sedentary and aging society. Dtsch Ärztbl Int. 2010;107(46):809-16.

4. Rick O, Metz T, Eberlein M, Schirren J, Bölükbas S. The six-minute-walk test in assessing respiratory function after tumor surgery of the lung: a cohort study. J Thorac Dis. 2014;6(5):421-8.

5. Pruthi N, MultaniNK. Influence of age on lung function tests. J Exercise Sci Physiother. 2012;8(1):1-6.

6. Bull FC, Maslin, TS, Armstrong T. Global physical activity questionnaire (GPAQ): nine country reliability and validity study. J Phys Act Health. 2009;6(6):790-804.

7. Hoos T, Espinoza N, Marshall S, Arredondo EM. Validity of the global physical activity questionnaire (GPAQ) in adult Latinas. J Phys Act Health. 2012;9(5):698-705.

8. Rao NA, Irfan M, Haque AS, Zubairi ABS, Awan S. Six-minute walk test performance in healthy adult Pakistani volunteers. J Coll Physicians Surg Pak. 2013;23(10):720-5.

9. Dourado VZ. Reference equations for the 6-minute walk test in healthy individuals. Arq Bras Cardiol. 2010:25(1):1-11.

10. Steffens D, Beckenkamp PR, Hancock M, Paiva DN, Alison JA, Menna-Barreto SS. Activity level predicts 6-minute walk distance in healthy older females: an observational study. Physiotherapy. 2012;99(1):21-6.

11. Camarri B, Eastwood PR, Cecins NM, Thompson PJ, Jenkins S. Six minute walk distance in healthy subjects aged 55-75 years. Respir Med. 2006;100(4):658-65.

12. Suwanachaiy S, Kulaputana O, ChaiwanichsiriD. Walk performance in Thai men and women: physical activity dependence. Asian Biomed. 2010;4(1):87-93.

13. Neto GAM, de Leon AP,Lira VA, Farinatti PTV. Assessment of cardiorespiratory fitness without exercise in elderly men with chronic cardiovascular and metabolic diseases. J Aging Res. 2012;2(8):1-6.

14. Nusdwinuringtyas N, Widjajalaksmi, Yunus F, Alwi I. Reference equation for prediction of a total distance during six-minute walk test using Indonesian anthropometrics. Acta Med Indones. 2014;46(2):9-6.

15. Sumirta IN. Implikasi gender terhadap kesehatan lansia. Bunga Rampai Kesehatan Lansia, http:/ramakrisnahareblogspotcoid. 2011.

16. Cleland CL, Hunter RF, Kee F, Cupples ME, Sallis JF, Tully MA. Validity of the global physical activity questionnaire (GPAQ) in assessing levels and change in moderate-vigorous physical activity and sedentary behaviour. BMC Public Health. 2014;14(1):1-11.

17. Santana P, Cintra RM, Rodrigues F. Correlation study on the results from measures of function and functionality tests of Portuguese COPD patients. Professional Assignment Project III-2. 2009:1-5.

18. Yusuff MR, Hussain MR, Norazizan S. Anthropometry dimensions of older Malaysians: comparison of age, gender and ethnicity. Asian Social Sci. 2009;5(6):133-40.

19. Albanese E, Davis B, Jonsson PV, Chang M, Aspelund T, Garcia M, et al. Overweight and obesity in midlife and brain structure and dementia 26 years later: the AGES-Reykjavik study. Am J Epidemiol. 2015;181(9):672-9.

20. Poh H, Eastwood PR, Cecins NM, Ho KT, Jenkins SC. Six-minute walk distance in healthy Singaporean adults cannot be predicted using reference equations derived from Caucasian populations. Respirology. 2006;11(2):211-6. 